\title{
Long-Term Follow-Up of Chronic Hepatitis C Patients Treated with Interferon-Alpha: Risk of Cirrhosis and Hepatocellular Carcinoma in a Single Center over 10 Years
}

\author{
Hyun Jung Lee Jong Eun Yeon Eileen L. Yoon Sang Jun Suh Keunhee Kang \\ Hae Rim Kim Seong Hee Kang Yang Jae Yoo Jihye Je Ji Hoon Kim \\ Yeon Seok Seo Hyung Joon Yim Kwan Soo Byun \\ Department of Internal Medicine, Korea University College of Medicine, Seoul, South Korea
}

\section{Key Words \\ Chronic hepatitis C . Cirrhosis - Hepatocellular carcinoma . \\ Interferon · Sustained virological response}

\begin{abstract}
Objectives: Interferon (IFN)-based therapy for chronic hepatitis $\mathrm{C}(\mathrm{CHC})$ is cost-effective and is associated with reduced risk of disease progression. We aimed to assess the incidence of cirrhosis and hepatocellular carcinoma (HCC) and to identify risk factors associated with disease progression. Methods: We retrospectively reviewed $280 \mathrm{CHC}$ patients who were registered at our hospital between 2001 and 2010. $R \boldsymbol{e}$ sults: About $80 \%$ of patients received antiviral treatment. The 10-year cumulative incidence of cirrhosis was significantly lower among patients who received antiviral therapy than among those who did not (8.3 vs. $44.0 \% ; p=0.001$ ). Among them, patients with sustained virological response (SVR) had a significantly lower incidence of cirrhosis than those without SVR (0.6 vs. 33.9\%; $p<0.001)$. Cox proportional hazards regression showed that SVR was the significant independent factor for reducing the risk of cirrhosis (hazard ratio, $\mathrm{HR}=0.03 ; \mathrm{p}=0.034$ ). The 10 -year cumulative incidence of HCC was higher among patients who did not receive antiviral therapy than among those who did (43.9 vs. $6.1 \%$; $p<$
\end{abstract}

0.001). Multivariate analysis showed that underlying cirrhosis was the only independent risk factor associated with HCC development ( $H R=7.70 ; p=0.010)$. Conclusions: SVR secondary to IFN-based therapy could reduce cirrhosis development in $\mathrm{CHC}$ patients. Underlying cirrhosis was the strongest predictor of HCC development.

(c) 2015 S. Karger AG, Basel

\section{Introduction}

Hepatitis $\mathrm{C}$ virus (HCV) infection is a main cause of chronic liver disease worldwide, affecting approximately 130-150 million people globally [1-3]. Of all HCV-infected individuals, 55-85\% develop chronic infection, and $15-30 \%$ of patients with chronic HCV infection develop cirrhosis. Within this population, hepatocellular carcinoma (HCC) occurs at an incidence of $1-5 \%$ per year [2-5].

In the early 2000s, the introduction of interferon (IFN)-based anti-HCV therapy brought many challenges in the management of HCV infection. A combination of peginterferon and ribavirin has been the standard therapy for patients with chronic hepatitis $\mathrm{C}(\mathrm{CHC})$ regardless of the genotype of the virus [6]. Treatment for $\mathrm{CHC}$ has

\section{KARGER 125}

(c) 2015 S. Karger AG, Basel

0300-5526/15/0581-0014\$39.50/0

E-Mail karger@karger.com

www.karger.com/int
Jong Eun Yeon, $\mathrm{MD}, \mathrm{PhD}$

Department of Internal Medicine, Guro Hospita

Korea University College of Medicine

97, Guro-Dong Gil, Guro-Dong, Guro-Ku, Seoul 152-703 (South Korea)

E-Mail jeyyeon@hotmail.com 
been found to be cost-effective and is associated with a reduced risk of liver disease progression. In a recent study investigating the cost-effectiveness of IFN therapy for HCV genotype 1 in a cohort of 4,000 patients, treatment during compensated cirrhosis resulted in improved survival and decreased cost compared with no treatment [7]. Also, the recent introduction of direct-acting antiviral agents such as boceprevir and telaprevir has been shown to improve sustained virological response (SVR) by up to $63-75 \%$ in treatment-naïve HCV genotype 1 patients [8]. Achievement of SVR after treatment has been associated with improvement in disease progression and liver histology, as well as a reduced risk of HCC and liver-related mortality [9-13].

Although the natural history of $\mathrm{CHC}$ and the effects of IFN-based therapy on disease progression have been extensively studied in previous reports, there have been few long-term follow-up studies since 2000. Consequently, the present study aimed to assess the incidence of disease progression to cirrhosis and the development of HCC and to evaluate the long-term effectiveness of anti-HCV therapy in patients with $\mathrm{CHC}$ in Korea during the past 10 years.

\section{Materials and Methods}

\section{Patients}

We retrospectively reviewed 523 patients who were registered as having CHC between January 2001 and December 2010 at Korea University College Guro Hospital, Seoul, South Korea. All patients tested positive for both anti-HCV antibodies and HCV RNA. Of this group, 243 patients met one of the following exclusion criteria: insufficient data or a follow-up period of $\leq 1$ year $(\mathrm{n}=$ $177)$, coinfection with hepatitis B virus $(n=9)$ or $\mathrm{HIV}(\mathrm{n}=1)$, acute hepatitis $\mathrm{C}(\mathrm{n}=1)$, or HCC that was detected within 12 months after the initial visit $(n=55)$. Consequently, 280 patients were enrolled for analysis.

Of the enrolled patients, 222 received antiviral treatment for at least 12 weeks. Treatment regimens consisted of either pegylated IFN monotherapy ( $\mathrm{n}=3$, hemodialysis patients) or combination therapy of pegylated IFN $(n=209)$ or IFN $(n=10)$ with ribavirin. For patients who received anti-HCV therapy, the starting point of follow-up was considered the time of initiation of antiviral treatment. For the 58 untreated patients, the starting point of follow-up was considered the first follow-up examination. Data collected by February 28, 2013 were used for analysis.

\section{Follow-Up and End Point Assessment}

All patients were followed up every 3-6 months (or more frequently, if required) for at least 1 year. Follow-up studies included conventional biochemical tests and abdominal ultrasonography or computed tomography (CT). Alcohol consumption was assessed as an all-or-none variable from medical records. Diabetes mellitus was diagnosed if fasting serum glucose levels exceeded
$126 \mathrm{mg} / \mathrm{dl}$ or if there was a need for insulin or an oral hyperglycemic drug to control glucose levels. The aspartate aminotransferase/alanine aminotransferase (AST/ALT) ratio was calculated from laboratory results exactly as described. A patient with SVR was defined as a patient showing clearance of HCV RNA by the end of treatment and at 6 months after the end of treatment. The other patients were classified as nonresponders. The study was approved by the institutional review board of Korea University College Guro Hospital.

The primary end points were disease progression to cirrhosis and the development of HCC. The diagnosis of cirrhosis was based on either histology or the presence of at least 2 of the following factors: documented varices, surface nodularity of the liver, splenomegaly, or platelet counts $<120 \times 10^{3} / \mu \mathrm{l}$. HCC was diagnosed by histological evaluation or clinically according to the guidelines of the Korean Liver Cancer Study Group and the National Cancer Center [14]. In brief, HCC was defined by one imaging technique (dynamic CT or dynamic MRI) showing an HCC-compatible feature in patients with an $\alpha$-fetoprotein level of $\geq 200 \mathrm{ng} / \mathrm{ml}$ or two imaging techniques (dynamic CT, dynamic MRI or hepatic artery angiography) showing an HCC-compatible feature in patients with an a-fetoprotein level of $<200 \mathrm{ng} / \mathrm{ml}$.

A chemiluminescence immunoassay was used to determine anti-HCV activity. COBAS AmpliPrep TM (Roche, Indianapolis, Ind., USA) was used to conduct a qualitative test of HCV RNA, and a PCR using an Abbott m2000rt instrument (Abbott Laboratories, Chicago, Ill., USA) was used to quantitatively measure the serum HCV RNA level (detection limit <50 IU/ml). The HCV genotype was amplified by PCR using the core region of the HCV cDNA, after which the DNA was sequenced.

\section{Statistical Analysis}

The baseline characteristics were summarized as percentages for categorical variables and as medians and interquartile ranges for continuous variables. Statistical analysis was performed using the $\chi^{2}$ test or Fisher's exact test to compare categorical variables and Student's t test or the Mann-Whitney U test to compare continuous variables. The cumulative incidence rates were determined using the Kaplan-Meier method, and the differences between groups were assessed with the log-rank test. We used the Cox proportional hazards regression analysis to examine the factors associated with the incidence of cirrhosis and HCC. The risk ratio attributable to responses to anti-HCV therapy was calculated using dummy variables (SVR vs. untreated and non-SVR vs. untreated). Variables with $\mathrm{p}$ values $<0.10$ in the univariate analysis were included the multivariate analysis. A $p$ value $<0.05$ was considered statistically significant. The analyses were performed with IBM SPSS Statistics 20 for Windows.

\section{Results}

\section{Patient Characteristics}

The baseline patient characteristics were compared between those patients who received anti-HCV therapy and those who did not (table 1). The two groups had comparable distributions of sex and HCV genotypes. Patients who received anti-HCV therapy tended to be younger 
Table 1. Baseline characteristics of the 280 patients at enrollment

\begin{tabular}{lccr}
\hline & $\begin{array}{l}\text { Patients with anti-HCV } \\
\text { therapy }(\mathrm{n}=222)\end{array}$ & $\begin{array}{l}\text { Patients without anti-HCV } \\
\text { therapy }(\mathrm{n}=58)\end{array}$ & p value \\
\hline Age, years & $55(47-63)$ & $63(52-71)$ & $<0.001$ \\
Male, $\mathrm{n}$ & $117(52.7 \%)$ & $31(53.4 \%)$ & 0.919 \\
BMI, kg/m & $23.6(21.9-25.4)$ & $23.8(21.7-25.1)$ & 0.953 \\
Alcohol use, $\mathrm{n}$ & $20(9.7 \%)$ & $5(14.3 \%)$ & 0.377 \\
Diabetes, $\mathrm{n}$ & $19(9 \%)$ & $7(18.9 \%)$ & 0.083 \\
AST, IU/l & $61(34-103)$ & $50(40-92)$ & 0.822 \\
ALT, IU/l & $58(30-126)$ & $55(27-111)$ & 0.289 \\
Albumin, g/dl & $4.2(4.1-4.4)$ & $4.1(3.8-4.3)$ & $<0.001$ \\
INR & $1.05(1.00-1.10)$ & $1.08(1.02-1.18)$ & 0.055 \\
Platelets $\left(\times 10^{3} / \mu \mathrm{l}\right)$ & $169(143-221)$ & $28(65-1 \%)$ & 0.002 \\
HCV RNA $>600,000 \mathrm{IU} / \mathrm{ml}$ & $124(58.8 \%)$ & $22(51.2 \%)$ & 0.439 \\
HCV genotype, $\mathrm{n}$ & $106(49.5 \%)$ & $21(48.8 \%)$ & 0.845 \\
$\quad$ Type 1 & $108(50.5 \%)$ & $17(29.3 \%)$ & $<0.001$ \\
$\quad$ Other & $20(9 \%)$ & &
\end{tabular}

than those who did not. The mean follow-up period was 4.1 years $(1-11.6)$ in patients who received anti-HCV therapy and 4.3 years $(1-11.7)$ in those who did not. The untreated group had significantly lower serum albumin and platelet levels than the treated group. Patients who received anti-HCV therapy had a lower rate of cirrhosis than those who did not ( 9 vs. $29.3 \%$; $p<0.001$ ).

Within the treated group, most patients $(94.1 \%)$ received combination therapy of pegylated IFN with ribavirin. Overall, SVR was observed in 167 of the 222 treated patients $(76.6 \%)$. A total of 63 patients with HCV genotype $1(60.0 \%)$ and 100 patients with HCV genotypes other than 1 (93.5\%) achieved SVR.

\section{Progression to Cirrhosis}

We assessed the incidence of cirrhosis development in patients without cirrhosis. A total of 243 patients were included in this analysis. Other than age, there were no significant differences in clinical characteristics between the patients who received anti-HCV therapy and those who did not (online suppl. table S1; for all online suppl. material, see www.karger.com/doi/10.1159/000369206). During a mean follow-up period of 4.1 years, a total of 17 patients $(7.0 \%)$ developed cirrhosis. Progression to cirrhosis was noted in 8 of the 202 patients who received anti-HCV therapy (4.0\%) and in 9 of the 41 patients who did not receive anti-HCV therapy $(22.0 \%)$. Figure 1a shows the cumulative incidence of cirrhosis. In patients who received anti-HCV therapy, the cumulative incidence rates of cirrhosis were $3.2,4.3$ and $8.3 \%$ at 3,5 and
10 years after starting therapy, respectively, with a mean annual incidence rate of $0.8 \%$. In patients who did not receive anti-HCV therapy, the cumulative incidence rates were $19.5,31.6$ and $44.0 \%$ at 3,5 and 10 years after enrollment, respectively, with a mean annual incidence rate of $4.4 \%$.

To determine which factors significantly influenced disease progression to cirrhosis, univariate and multivariate analyses were performed. The univariate analysis was performed with the following 11 variables: age, sex, alcohol intake, BMI, albumin level, platelet count, international normalized ratio (INR), AST/ALT ratio, genotype, antiviral treatment (indicating no SVR), and presence of cirrhosis. In that analysis, the following 4 factors were shown to have significantly affected disease progression to cirrhosis: age $\geq 60$, albumin $\leq 3.5 \mathrm{~g} / \mathrm{dl}$, platelets $\leq 120 \times$ $10^{3} / \mu \mathrm{l}$, and antiviral treatment (no SVR). A multivariate analysis showed that SVR (hazard ratio, $\mathrm{HR}=0.03$; confidence interval, $\mathrm{CI}=0.00-0.27 ; \mathrm{p}=0.034$ ) and a platelet count $\leq 120 \times 10^{3} / \mu \mathrm{l}(\mathrm{HR}=3.35 ; \mathrm{CI}=1.12-9.99 ; \mathrm{p}=0.030)$ were independent factors for cirrhosis development (table 2). Further analysis of SVR showed that the 9.3-year cumulative incidence of cirrhosis was significantly lower in patients with SVR $(0.6 \%)$ than in those without SVR $(33.9 \%$; $\mathrm{p}<0.001)$ or in untreated patients $(44.0 \%$; $\mathrm{p}<$ 0.001 ; fig. 1b). The cumulative incidence of cirrhosis did not differ between patients without SVR and untreated patients $(\mathrm{p}=0.446)$.

During the follow-up period, clinical decompensation developed in 12 out of 54 cirrhotic patients (22.2\%).
16

Intervirology 2015;58:14-21 DOI: $10.1159 / 000369206$
Lee/Yeon/Yoon/Suh/Kang/Kim/Kang/ Yoo/Je/Kim/Seo/Yim/Byun 


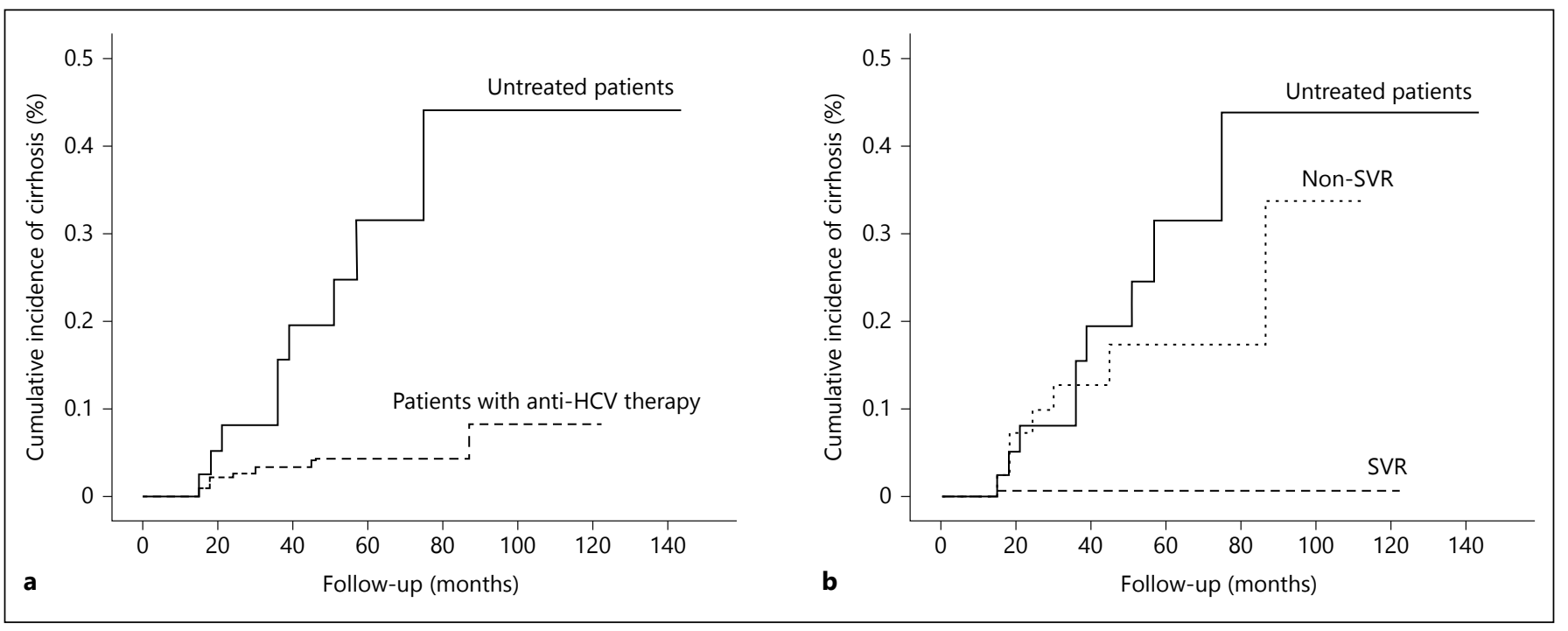

Fig. 1. The cumulative incidence of cirrhosis among $\mathrm{CHC}$ patients $(n=243)$. a The 10 -year cumulative incidence was $8.3 \%$ in patients who received anti-HCV treatment and $44.0 \%$ in untreated patients $(\mathrm{p}=0.001)$. $\mathbf{b}$ The 9.3 -year cumulative incidence was $0.6 \%$ in pa-

tients with SVR, 33.9\% in those without and $44.0 \%$ in untreated patients (SVR vs. non-SVR, $\mathrm{p}<0.001$; SVR vs. untreated patients, $\mathrm{p}<0.001$; non-SVR vs. untreated patients, $\mathrm{p}=0.446$ ). All $\mathrm{p}$ values were obtained using the log-rank test.

Table 2. Cox multivariate regression analysis for progression to cirrhosis $(n=243)$

\begin{tabular}{lll}
\hline Variables & HR & p value \\
\hline Age $\geq 60$ years & $2.15(0.74-6.31)$ & 0.162 \\
Albumin $\leq 3.5 \mathrm{~g} / \mathrm{dl}$ & $1.62(0.32-8.23)$ & 0.562 \\
Platelets $\leq 120\left(\times 10^{3} / \mu \mathrm{l}\right)$ & $3.35(1.12-9.99)$ & 0.030 \\
Response to anti-HCV therapy & & \\
$\quad$ Untreated control & 1 & \\
$\quad$ No SVR & $0.68(0.25-1.86)$ & 0.450 \\
SVR & $0.03(0.00-0.27)$ & 0.034 \\
\hline
\end{tabular}

Values in parentheses are $95 \% \mathrm{CI}$.

Most ( 9 patients) had cirrhosis at baseline. The most common clinical cause of decompensation was ascites, which occurred in 9 patients (16.7\%). Other events included variceal bleeding in 6 patients $(11.1 \%)$, hepatic encephalopathy in 3 patients (5.6\%) and jaundice in 3 patients $(5.6 \%)$.

\section{Development of HCC}

During the mean follow-up period of 4.2 years, HCC developed in a total of 17 patients (6.1\%), including 5 of the 222 patients who received anti-HCV therapy (2.3\%) and 12 of the 58 patients who did not receive anti-HCV therapy (20.7\%). All of these patients had either preexist- 


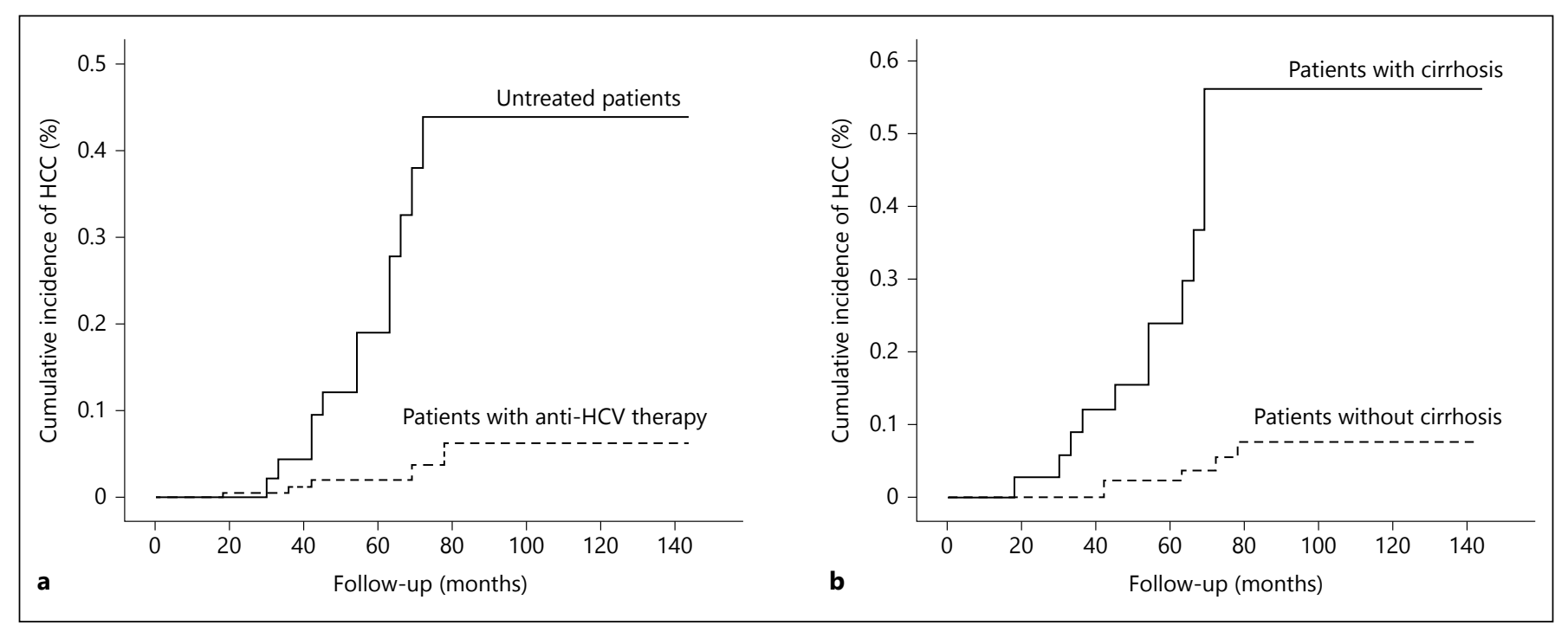

Fig. 2. The cumulative incidence of HCC among CHC patients $(\mathrm{n}=280)$. a The 11.8 -year cumulative incidence was $6.1 \%$ in patients who received anti-HCV treatment and $43.9 \%$ in untreated patients $(\mathrm{p}<0.001)$. $\mathbf{b}$ The 11.8 -year cumulative incidence of HCC

Table 3. Cox multivariate regression analysis for the development of $\operatorname{HCC}(n=280)$

\begin{tabular}{lll}
\hline Variables & HR & p value \\
\hline Age $\geq 60$ years & $2.39(0.62-9.18)$ & 0.203 \\
Albumin $\leq 3.5 \mathrm{~g} / \mathrm{dl}$ & $0.97(0.24-3.88)$ & 0.962 \\
Platelets $\leq 120\left(\times 10^{3} / \mu \mathrm{l}\right)$ & $1.95(0.35-10.98)$ & 0.451 \\
INR $\geq 1.5$ & $5.68(0.49-66.51)$ & 0.166 \\
Response to anti-HCV therapy & & \\
$\quad$ Untreated control & 1 & \\
$\quad$ No SVR & $0.52(0.09-3.17)$ & 0.479 \\
$\quad$ SVR & $0.33(0.07-1.52)$ & 0.154 \\
Cirrhosis & $7.70(1.64-36.14)$ & 0.010 \\
\hline
\end{tabular}

Values in parentheses are $95 \% \mathrm{CI}$.

cirrhosis $(56.3 \%)$ than in those without $(7.6 \%$; $\mathrm{p}<0.001)$. The 10-year cumulative incidence of HCC did not differ between patients with SVR and those without (6.3 vs. $6.1 \% ; \mathrm{p}=0.402)$.

Among the 37 patients with cirrhosis, 20 received IFNbased treatment. The 6-year cumulative incidence of HCC in patients with cirrhosis was significantly lower in patients who received anti-HCV therapy $(28.9 \%)$ than in those who did not $(81.8 \% ; \mathrm{p}=0.019)$. However, there was no difference between patients with SVR and those without $(\mathrm{p}=0.634)$.

18 was $7.6 \%$ in patients without cirrhosis and $56.3 \%$ in patients with cirrhosis $(\mathrm{p}<0.001)$. All $\mathrm{p}$ values were obtained using the log-rank test.

\section{Discussion}

In chronic $\mathrm{HCV}$ infection, liver disease progression takes place over several decades and depends on the presence of several cofactors, including alcohol consumption, diabetes mellitus, age of acquisition, and coinfection with other viruses such as HIV and hepatitis $B$ virus $[1,2]$. Treatment response is also affected by several factors, including the genotype and stage of fibrosis $[1,2]$. Traditionally, Asian patients with chronic HCV infection have a better chance to achieve SVR, even in cases of HCV genotype 1 [15]. In a study of Korean patients with chronic HCV infection, the SVR rate was $53.6 \%$ for patients with genotype 1 and $71.4 \%$ for patients with genotype $2 / 3$ [16]. These higher SVR rates in Korean patients seem to be partly explained by a higher proportion of favorable $I L-28 B$ polymorphisms [17]. Also, the demographic patterns, including risk factors and genotype distribution, of the Korean HCV patients were different from those of other countries [18]. The natural history and risk factors for disease progression of chronic HCV infection have primarily been studied in Western countries or Japan, and there is little information on Korean patients $[5,19,20]$. Thus, the current study has provided some useful information about this population.

Although the rate of progression to cirrhosis is affected by various factors, previous studies have reported 
that the annual incidence of cirrhosis is approximately 2.26-5\% in untreated patients with chronic HCV infection $[2,10,21]$. The incidence of cirrhosis in our patients who did not receive anti-HCV therapy (4.4\%) was not different from incidences reported in previous studies. Our findings showed that anti-HCV therapy reduced the annual incidence of cirrhosis in the 202 treated patients $(0.8 \%)$. Our study also revealed that the incidence of cirrhosis varied according to patient response to anti-HCV therapy: patients with SVR had a significantly lower cumulative incidence of cirrhosis than patients without SVR (9.3-year cumulative incidence: 0.6 vs. $33.9 \%$ ).

Furthermore, our multivariate analysis demonstrated a beneficial effect of SVR for preventing disease progression to cirrhosis in patients with chronic HCV infection. The HR for disease progression to cirrhosis was 3.0 for the patients without anti-HCV therapy and 1.6 for the patients without SVR. This finding is consistent with that of several other reports, suggesting that patients who respond differently to anti-HCV therapy have a different incidence of disease progression to cirrhosis [12, 22, 23]. In a large-scale, nationwide, multicenter study in Taiwan, the annual incidences of cirrhosis in an untreated group, an IFN-treated group without SVR, and an IFN-treated group with SVR were 2.26, 1.99 and $0.74 \%$, respectively [10]. Bruno et al. [24] and Shiratori et al. [13] assessed changes in liver histology after IFN therapy. Both studies demonstrated that liver histology progressively improved in patients with SVR, whereas untreated patients and patients without SVR had unchanged fibrosis. Although the present study did not confirm the cirrhosis development by histology, our study provided a longer period (over 10 years) of observation addressing the long-term benefits of anti-HCV therapy. In our multivariate analysis, low platelet count was also an independent factor for disease progression to cirrhosis. The platelet count reflects the severity of $\mathrm{CHC}$ and is traditionally used to estimate the degree of fibrosis $[25,26]$. Our findings indicated that platelet count, as well as antiviral response, could be used to stratify the risk of disease progression to cirrhosis in patients with $\mathrm{CHC}$.

In the present study, preexisting liver cirrhosis was the only significant independent risk factor for HCC development ( $\mathrm{HR}=7.70 ; \mathrm{p}=0.010)$. This result is consistent with almost all clinical studies; advanced fibrosis and cirrhosis are the strongest predictors of HCC development $[9,27-30]$. The incidence of HCC with $\mathrm{CHC}$ and cirrhosis is estimated at $1-4 \%$ per year $[1,2]$. The overall annual incidence rates of HCC in our study were
$0.6 \%$ for patients who received anti-HCV therapy and $4.4 \%$ for patients who did not. This relatively high incidence of HCC in the patients who did not receive anti$\mathrm{HCV}$ therapy might be a result of selection bias. Reasons for not receiving anti-HCV therapy included the presence of cirrhosis, as well as older age (table 1). In the present study, $30 \%$ of patients had cirrhosis, and $>50 \%$ were aged $>60$ years, which would have excluded them from treatment. This is a limitation of this retrospective study.

The present study demonstrated in a univariate analysis that a favorable response to treatment is associated with a lower risk of HCC development, but this result failed to reach statistical significance $(\mathrm{p}=0.154)$ in a multivariate model. Recently, however, SVR after treatment of $\mathrm{HCV}$-infected persons at any stage of fibrosis has been associated with a low rate of progression towards decompensation or HCC [31-37]. In the current study, approximately $70 \%$ of the patients $(n=12)$ who developed HCC were included in the untreated group. Most of them had underlying cirrhosis and would have been excluded from anti-HCV treatment. The study included a relatively small number of patients, and the resulting selection bias (presence of cirrhosis) might have affected the results, indicating no beneficial role of SVR in preventing HCC. To eliminate the effect of cirrhosis, we analyzed the development of HCC in only the patients without cirrhosis $(\mathrm{n}=243)$. In multivariate analysis, $\mathrm{SVR}(\mathrm{HR}=0.09$; $\mathrm{CI}=$ $0.01-0.76 ; p=0.028)$ was the only factor that was independently associated with the development of HCC (online suppl. table S2). Recently, there is increasing evidence that SVR at week 12 was equivalent to SVR at week 24 for guiding dosing and treatment strategies. Further studies on the effect of early SVR (SVR 12) for predicting the development of cirrhosis and HCC are warranted [38].

This study had several limitations. It was not a prospective controlled trial, which may confound the interpretation of results. In addition, it included a small number of patients, and the age distribution and proportion of patients with cirrhosis were not well matched between the treated and untreated groups. For ethical reasons, however, it is difficult to perform a prospective study on the effectiveness of anti-HCV therapy in preventing disease progression to cirrhosis and the development of HCC. Another limitation is selection and referral bias. Our center is a tertiary center, and so the patients in our study may differ from patients in the overall community. To overcome these limitations, the use of propensity score analysis or a large multicenter cohort is required 
[39]. However, our study did provide a relatively long period of observation, thereby addressing the long-term effect of anti-HCV therapy on disease progression to cirrhosis.

In conclusion, the current study demonstrated that SVR secondary to anti-HCV therapy could reduce cirrhosis development in $\mathrm{CHC}$ patients. The strongest predictor for the development of HCC was underlying cirrhosis. Thus, patients with cirrhosis need close monitor- ing for the development of HCC, and future studies on achieving SVR are warranted to prevent disease progression to cirrhosis.

\section{Disclosure Statement}

The authors declare that they have nothing to disclose regarding funding or conflicts of interest with respect to this manuscript.

\section{References}

1 Lavanchy D: The global burden of hepatitis C. Liver Int 2009;29(suppl 1):74-81.

12 Afdhal NH: The natural history of hepatitis C. Semin Liver Dis 2004;24(suppl 2):3-8.

3 WHO: Hepatitis C. http://www.who.int/ mediacentre/factsheets/fs164/en/index.html (updated April 2014).

$\checkmark 4$ Thompson Coon J, Rogers G, Hewson P, Wright D, Anderson R, Cramp M, Jackson S, Ryder S, Price A, Stein K: Surveillance of cirrhosis for hepatocellular carcinoma: systematic review and economic analysis. Health Technol Assess 2007;11:1-206.

5 Davis GL, Alter MJ, El-Serag H, Poynard T, Jennings LW: Aging of hepatitis $\mathrm{C}$ virus (HCV)-infected persons in the United States: a multiple cohort model of HCV prevalence and disease progression. Gastroenterology 2010;138:513-521.

-6 Strader DB, Wright T, Thomas DL, Seeff LB: Diagnosis, management, and treatment of hepatitis C. Hepatology 2004;39:1147-1171.

7 Saab S, Hunt DR, Stone MA, McClune A, Tong MJ: Timing of hepatitis $C$ antiviral therapy in patients with advanced liver disease: a decision analysis model. Liver Transpl 2010; 16:748-759.

8 Ghany MG, Nelson DR, Strader DB, Thomas DL, Seeff LB: An update on treatment of genotype 1 chronic hepatitis $C$ virus infection: 2011 practice guideline by the American Association for the Study of Liver Diseases. Hepatology 2011;54:1433-1444.

-9 Hung $\mathrm{CH}$, Lee $\mathrm{CM}$, Wang JH, Hu TH, Chen $\mathrm{CH}$, Lin CY, Lu SN: Impact of diabetes mellitus on incidence of hepatocellular carcino$\mathrm{ma}$ in chronic hepatitis $\mathrm{C}$ patients treated with interferon-based antiviral therapy. Int J Cancer 2011;128:2344-2352.

10 Huang JF, Yu ML, Lee CM, Dai CY, Hou NJ, Hsieh MY, Wang JH, Lu SN, Sheen IS, Lin SM, Chuang WL, Liaw YF: Sustained virological response to interferon reduces cirrhosis in chronic hepatitis C: a 1,386-patient study from Taiwan. Aliment Pharmacol Ther 2007; 25:1029-1037.

11 Kurokawa M, Hiramatsu N, Oze T, Mochizuki K, Yakushijin T, Kurashige N, Inoue Y, Igura $\mathrm{T}$, Imanaka $\mathrm{K}$, Yamada A, Oshita M,
Hagiwara $\mathrm{H}$, Mita E, Ito T, Inui Y, Hijioka T, Yoshihara $\mathrm{H}$, Inoue A, Imai $\mathrm{Y}$, Kato M, Kiso S, Kanto T, Takehara T, Kasahara A, Hayashi $\mathrm{N}$ : Effect of interferon alpha-2b plus ribavirin therapy on incidence of hepatocellular carcinoma in patients with chronic hepatitis. Hepatol Res 2009;39:432-438.

12 Papatheodoridis GV, Papadimitropoulos VC, Hadziyannis SJ: Effect of interferon therapy on the development of hepatocellular carcinoma in patients with hepatitis $C$ virus-related cirrhosis: a meta-analysis. Aliment Pharmacol Ther 2001;15:689-698.

13 Shiratori Y, Imazeki F, Moriyama M, Yano M, Arakawa Y, Yokosuka O, Kuroki T, Nishiguchi S, Sata M, Yamada G, Fujiyama S, Yoshida $\mathrm{H}$, Omata M: Histologic improvement of fibrosis in patients with hepatitis $\mathrm{C}$ who have sustained response to interferon therapy. Ann Intern Med 2000;132:517-524.

14 Korean Liver Cancer Study Group and National Cancer Center Korea: Practice guidelines for management of hepatocellular carcinoma 2009 (in Korean). Korean J Hepatol 2009;15:391-423.

15 Missiha S, Heathcote J, Arenovich T, Khan K: Impact of Asian race on response to combination therapy with peginterferon alfa-2a and ribavirin in chronic hepatitis C. Am J Gastroenterol 2007;102:2181-2188.

16 Park SH, Park CK, Lee JW, Kim YS, Jeong SH, Kim JH, Hwang SG, Rim KS, Yim HJ, Cheong JY, Cho SW, Lee JS, Park YM, Jang JW, Lee CK, Shon JH, Yang JM, Ju YS: Efficacy and tolerability of peginterferon-alpha plus ribavirin in the routine daily treatment of chronic hepatitis C patients in Korea: a multi-center, retrospective observational study. Gut Liver 2012;6:98-106.

17 Jung YK, Kim JH, Ahn SM, Yang JW, Park SJ, Kim JW, Yeon JE, Kwon OS, Kim YS, Choi DJ, Byun KS: Role of interleukin 28Brelated gene polymorphisms in chronic hepatitis $C$ and the response to antiviral therapy in Koreans. J Clin Gastroenterol 2013;47: 644-650.

-18 Seong MH, Kil H, Kim YS, Bae SH, Lee YJ, Lee $\mathrm{HC}$, Kang BH, Jeong SH: Clinical and epidemiological features of hepatitis $\mathrm{C}$ virus infec- tion in South Korea: a prospective, multicenter cohort study. J Med Virol 2013;85: 1724-1733.

19 Carney K, Dhalla S, Aytaman A, Tenner CT, Francois F: Association of tattooing and hepatitis $C$ virus infection: a multicenter casecontrol study. Hepatology 2013;57:21172123.

20 Mele A, Spada E, Sagliocca L, Ragni P, Tosti ME, Gallo G, Moiraghi A, Balocchini E, Sangalli M, Lopalco PL, Stroffoli T: Risk of parenterally transmitted hepatitis following exposure to surgery or other invasive procedures: results from the hepatitis surveillance system in Italy. J Hepatol 2001;35:284-289.

21 Shindo M, Ken A, Okuno T: Varying incidence of cirrhosis and hepatocellular carcinoma in patients with chronic hepatitis $\mathrm{C}$ responding differently to interferon therapy. Cancer 1999;85:1943-1950.

22 Nishiguchi S, Shiomi S, Nakatani S, Takeda T, Fukuda K, Tamori A, Habu D, Tanaka T: Prevention of hepatocellular carcinoma in patients with chronic active hepatitis $\mathrm{C}$ and cirrhosis. Lancet 2001;357:196-197.

23 International Interferon- $\alpha$ Hepatocellular Carcinoma Study Group: Effect of interferon- $\alpha$ on progression of cirrhosis to hepatocellular carcinoma: a retrospective cohort study. Lancet 1998;351:1535-1539.

24 Bruno S, Zuin M, Crosignani A, Rossi S, Zadra F, Roffi L, Borzio M, Redaelli A, Chiesa A, Silini EM, Almasio PL, Maisonneuve P: Predicting mortality risk in patients with compensated HCV-induced cirrhosis: a longterm prospective study. Am J Gastroenterol 2009;104:1147-1158.

25 Matsumura H, Moriyama M, Goto I, Tanaka $\mathrm{N}$, Okubo H, Arakawa Y: Natural course of progression of liver fibrosis in Japanese patients with chronic liver disease type $\mathrm{C}-\mathrm{a}$ study of 527 patients at one establishment. J Viral Hepat 2000;7:268-275.

26 Pohl A, Behling C, Oliver D, Kilani M, Monson $\mathrm{P}$, Hassanein T: Serum aminotransferase levels and platelet counts as predictors of degree of fibrosis in chronic hepatitis $\mathrm{C}$ virus infection. Am J Gastroenterol 2001;96:31423146. 
27 Asahina Y, Tsuchiya K, Tamaki N, Hirayama I, Tanaka T, Sato M, Yasui Y, Hosokawa T, Ueda K, Kuzuya T, Nakanishi H, Itakura J, Takahashi Y, Kurosaki M, Enomoto N, Izumi $\mathrm{N}$ : Effect of aging on risk for hepatocellular carcinoma in chronic hepatitis $\mathrm{C}$ virus infection. Hepatology 2010;52:518-527.

28 Kawamura Y, Arase Y, Ikeda K, Hirakawa M, Hosaka T, Kobayashi M, Saitoh S, Yatsuji H, Sezaki H, Akuta N, Suzuki F, Suzuki Y, Kumada H: Diabetes enhances hepatocarcinogenesis in noncirrhotic, interferon-treated hepatitis C patients. Am J Med 2010;123:951956.e951.

29 Takahashi H, Mizuta T, Eguchi Y, Kawaguchi Y, Kuwashiro T, Oeda S, Isoda H, Oza N, Iwane S, Izumi K, Anzai K, Ozaki I, Fujimoto $\mathrm{K}$ : Post-challenge hyperglycemia is a significant risk factor for the development of hepatocellular carcinoma in patients with chronic hepatitis C. J Gastroenterol 2011;46:790-798.

-30 Tateyama M, Yatsuhashi H, Taura N, Motoyoshi Y, Nagaoka S, Yanagi K, Abiru S, Yano K, Komori A, Migita K, Nakamura M, Nagahama H, Sasaki Y, Miyakawa Y, Ishibashi H: Alpha-fetoprotein above normal levels as a risk factor for the development of hepatocellular carcinoma in patients infected with hepatitis C virus. J Gastroenterol 2011;46:92-100.
$31 \mathrm{Ng} \mathrm{V}$, Saab S: Effects of a sustained virologic response on outcomes of patients with chronic hepatitis C. Clin Gastroenterol Hepatol 2011;9:923-930.

32 Morgan RL, Baack B, Smith BD, Yartel A, Pitasi M, Falck-Ytter Y: Eradication of hepatitis $\mathrm{C}$ virus infection and the development of hepatocellular carcinoma: a meta-analysis of observational studies. Ann Intern Med 2013; 158:329-337.

33 Braks RE, Ganne-Carrie N, Fontaine H, Paries J, Grando-Lemaire V, Beaugrand M, Pol S, Trinchet JC: Effect of sustained virological response on long-term clinical outcome in 113 patients with compensated hepatitis C-related cirrhosis treated by interferon-alpha and ribavirin. World J Gastroenterol 2007;13: 5648-5653.

34 Tsuda N, Yuki N, Mochizuki K, Nagaoka T, Yamashiro M, Omura M, Hikiji K, Kato M: Long-term clinical and virological outcomes of chronic hepatitis $\mathrm{C}$ after successful interferon therapy. J Med Virol 2004;74: 406-413.
5 Di Marco V, Almasio PL, Ferraro D, Calvaruso V, Alaimo G, Peralta S, Di Stefano R, Craxi A: Peg-interferon alone or combined with ribavirin in HCV cirrhosis with portal hypertension: a randomized controlled trial. J Hepatol 2007;47:484-491.

36 Morisco F, Granata R, Stroffolini T, Guarino M, Donnarumma L, Gaeta L, Loperto I, Gentile I, Auriemma F, Caporaso N: Sustained virological response: a milestone in the treatment of chronic hepatitis C. World J Gastroenterol 2013;19:2793-2798.

37 Gentile I, Borgia G: Surrogate endpoints and non-inferiority trials in chronic viral hepatitis. J Hepatol 2010;52:778.

38 Chen J, Florian J, Carter W, Fleischer RD, Hammerstrom TS, Jadhav PR, Zeng W, Murray J, Birnkrant D: Earlier sustained virologic response end points for regulatory approval and dose selection of hepatitis $C$ therapies. Gastroenterology 2013;144:1450-1455.e1452.

39 Tanimoto Y, Tashiro H, Aikata H, Amano H, Oshita A, Kobayashi T, Kuroda S, Tazawa H, Takahashi S, Itamoto T, Chayama K, Ohdan $\mathrm{H}$ : Impact of pegylated interferon therapy on outcomes of patients with hepatitis $\mathrm{C}$ virusrelated hepatocellular carcinoma after curative hepatic resection. Ann Surg Oncol 2012; 19:418-425. 